\title{
Integrating Cryptocurrency into Intermediate Financial Accounting Curriculum: A Case Study
}

\author{
Tatyana S. Ryabova \\ California State University, Fresno \\ Susan Henderson \\ California State University, Fresno
}

As the accounting profession is rapidly changing, faculty members are challenged with the task of incorporating emerging advances into the accounting curriculum in order to equip students for future success. There is little debate that cryptocurrency is prominent in the business world today, thus prompting attention for accounting professionals and educators is important. In this paper, we document our experiences in introducing cryptocurrencies to undergraduate financial accounting students with the goal of capturing their knowledge and measuring their perceptions of the impact digital currency holds in the current economic environment. To operationalize our research question, students were given a cryptocurrency assignment to complete outside of class and were asked a series of questions in the class period directly after the assignment was due. The results of our case study show that students became more aware of cryptocurrencies and accounting practices associated with them after their completion of this assignment and the vast majority of students found this knowledge would benefit them in their future careers.

Keywords: Accounting for Cryptocurrencies, Bitcoin, Blockchain

\section{INTRODUCTION}

The purpose of this case study is to investigate the role cryptocurrency plays in the accounting environment in order to assess whether this topic should be introduced into an intermediate financial accounting curriculum. In the current economic environment, digital assets have a market capitalization exceeding \$228 Billion (CoinMarketCap, 2019) which has generated a great deal of attention from accounting professionals and accounting standard setting bodies in order to address and resolve the issues that these types of assets have generated. As cryptocurrencies continue to hold a strong position in our financial markets, we now need to investigate the inclusion of these types of assets in the financial accounting courses. This research aims to contribute to the current literature by extending the cryptocurrency discussions into the classroom.

To operationalize our research, we designed an assignment surrounding cryptocurrencies which emphasized student investigation into this topic based on a general rubric. This assignment provided an opportunity for students to branch out into areas that interested them into this topic and allowed us to 
measure student's reactions to the assignment by administering a survey directly after our in-class discussion. Based on our survey, we found that most students were not exposed to cryptocurrencies in their business school curriculum and their knowledge prior to the assignment was very limited. Additionally, approximately $89 \%$ of students indicated that they would like to learn more about cryptocurrencies and $98 \%$ of students felt that knowing more about this topic would benefit their future. Based on our review of the current literature, the presence of cryptocurrencies in the financial markets is remarkable prevalent; these results support the notion that students also see the benefit of incorporating digital assets into their accounting courses to prepare them for the jobs in the financial accounting sector.

The remainder of the paper is organized as follows: Section II will provide a review of the existing business literature as it relates to cryptocurrency and regulation, Section III discusses the parameters of the case study, Section IV will discuss the results and Section V will provide our conclusions, limitations, and suggestions for future researches.

\section{LITERATURE REVIEW}

\section{Cryptocurrency}

Cryptocurrency is a digital form of the money that functions in conjunction with a technique called cryptography. Cryptography refers to a process that translates legible information into codes that cannot be broken (Milutinović, 2018). According to Deloitte (2018), cryptocurrency is a new type of value and payment method that is distinctly different from fiat currency (e.g., U.S. dollars and foreign currencies). As of May 2019, there are 2,182 different types of digital assets in circulation such as Bitcoin, Ethereum, Litecoin, Monero, etc. The market capitalization for digital assets exceeds US\$228 billion (CoinMarketCap, 2019). Bitcoin is still the dominant cryptocurrency after 10 years since its creation (see Figure 1).

\section{PERCENTAGE OF TOTAL MARKET CAPITALIZATION (DOMINANCE)}

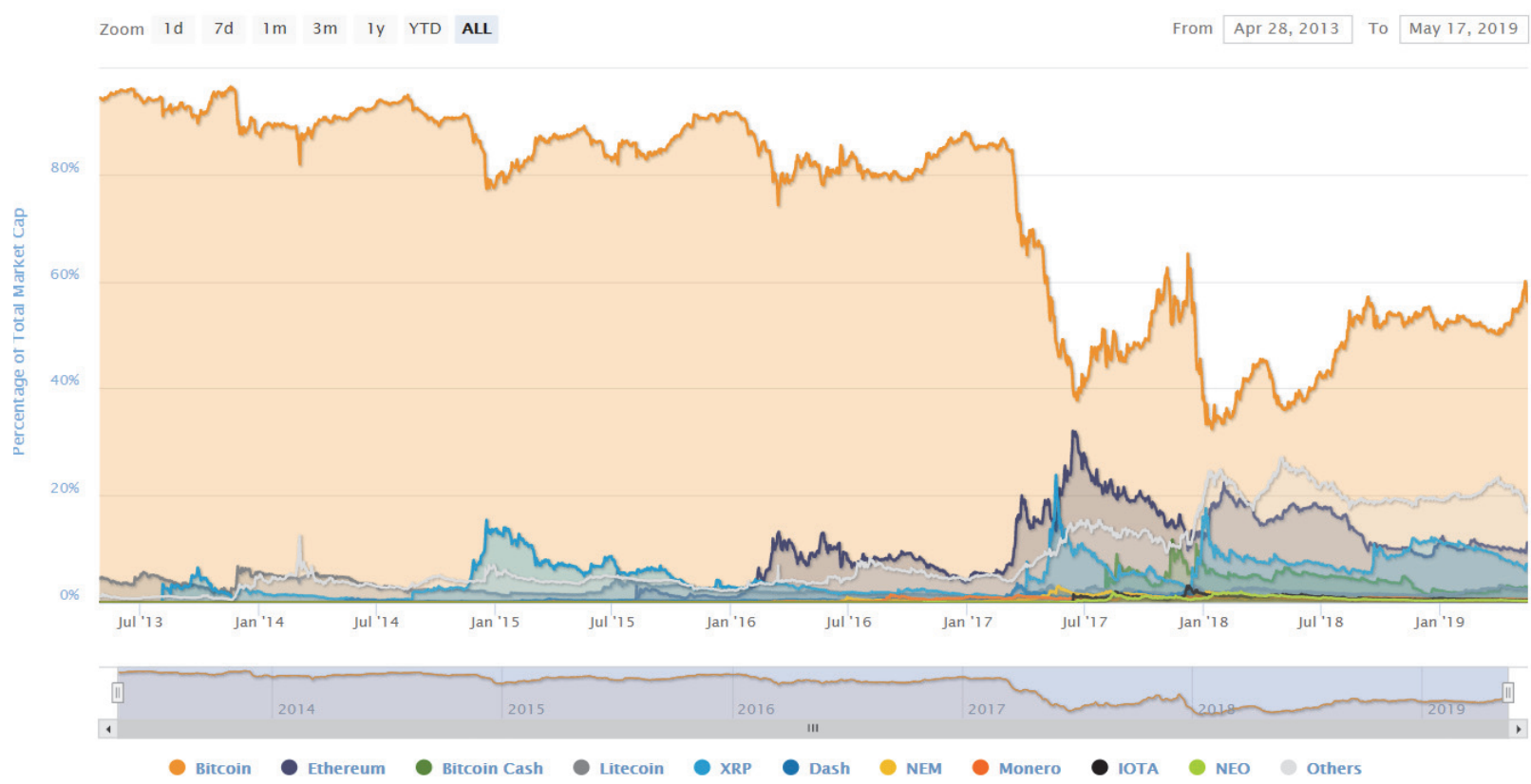

Source: CoinMarketCap (2019). Top 100 Cryptocurrencies by Market Capitalization, Retrieved on May 17, 2019, https://coinmarketcap.com/ 
Satoshi Nakamoto is cited as being the chief inventor of Bitcoin in late 2008. However, many believe that Satoshi Nakamoto is a pseudonym and a group of people rather than one individual (Popper, 2015). Nonetheless, Nakamoto was able to counteract the need for a central server by adopting a Peer-to-Peer (P2P) methodology. This approach allows each computer to keep a continuous roll of balance activities, and does not proceed until each $\mathrm{P} 2 \mathrm{P}$ device agrees with each other; once every device agrees, the transaction will be verified and recorded. With the creation of this new method, cryptocurrency revolutionizes the world of accounting and finance by adapting to technology that is unique to the $21^{\text {st }}$ century. It finally addresses the dilemma that has plagued other currencies from prospering; which is the ability to record, analyze, and save all transactions without a centralized processing server. Although blockchain was created to facilitate Bitcoin, the technology behind blockchain now extends far beyond the world of cryptocurrency. An important facet of blockchain technology is that it is decentralized therefore eliminates the middlemen. Rather than storing data in one location, blockchain technology shares data across a massive peer-to-peer network. Until now, we have relied on institutions or trusted third parties, such as banks, government registries, and other intermediaries, to be in the middle of our transactions to create validity (Vetter, 2018).

Based on our review, mining is a key piece for digital currency. A miner is someone who utilizes computers to perform calculations in order to confirm transactions on the blockchain and with permission-less mining, theoretically, anyone could become a miner. Success in this endeavor is paid in Bitcoin or another chain's native currency (Blockgeeks.com, 2018). "Jan. 13, 2018 marked an important milestone for Bitcoin when 16.8 million Bitcoins, or 80 percent of the entire Bitcoin supply, were mined. This means only 4.2 million bitcoins, or 20 percent, are left to mine until Bitcoin's 21 million supply cap is reached" (Zuckerman, 2018). Prior to the creation of this case study, our knowledge regarding cryptocurrency was very limited and we found helpful depictions fostered our knowledge more efficiently. Refer to Figure 2 on how cryptocurrencies work.

FIGURE 2

\section{HOW CRYPTOCURRENCIES WORK?}

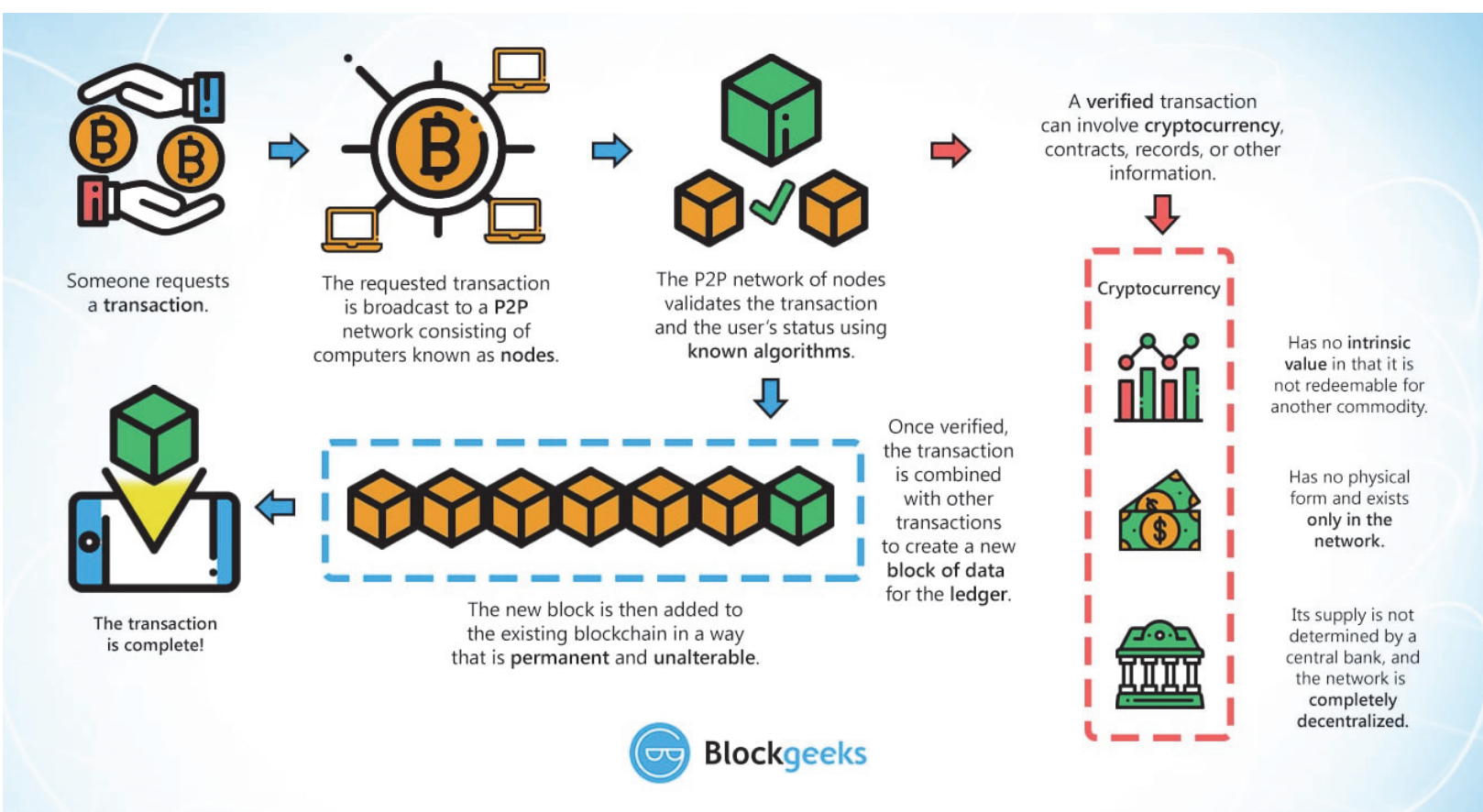

Source: Blockgeeks (2019). What is Cryptocurrency: Everything You Must Need To Know! Retrieved May 2019, https://blockgeeks.com/guides/what-is-cryptocurrency 
Based on our review, many people feel cryptocurrencies, like Bitcoin, will be the future of currency by surpassing the effects of inflation and loss of value exhibited in many countries' native currency (Blockgeeks.com, 2018). All of this enthusiasm is carried with the fact that cryptocurrency is regulated only by peer to peer technology, coding, math, and cryptology, without any government regulation, insisting to any investor the sense of a laissez-faire world economy (Blockgeeks.com, 2018). According to Drew (2018), the accounting profession sits on the cusp of this unprecedented change. Transformative technologies such as blockchain, automated data analytics and artificial intelligence (AI) will reshape virtually every corner of the accounting world by changing the way Certified Public Accountants (CPAs) work, whom they work with, where they do their jobs and how they connect with clients and colleagues. Moreover, firms such as Deloitte (2016) believe that blockchain technology could end up succeeding double-entry accounting, which has been in practice since 1494. Some PwC and EY offices accept bitcoin as a form of payment for certain services (Vetter, 2018). This adaptation to use cryptocurrencies provides substantial evidence that digital assets are not only pervasive in our capital markets but becoming revolutionary in the accounting world. This notion gives educators even more motivation to educate themselves on this new technology with the intent of passing knowledge to their students in order to prepare them for their future careers.

\section{Regulation and Cryptocurrency}

This section will investigate the reaction accounting standard bodies and regulators have had to digital currencies and what they are doing to address the issues these cryptocurrencies present. Interestingly, United States GAAP does not directly provide guidance on the accounting for cryptocurrencies (Deloitte, 2018), but they are actively working to address this shortcoming. More specifically, the Financial Accounting Standards Board (FASB) meeting minutes dated October 9, 2018 indicated that the organization has some learning to do concerning cryptocurrencies:

The FASB chairman asked for clarity on the specifics of the accounting issues related to cryptocurrencies. A PCC (Private Company Council) member explained that there are both accounting and auditing issues, and most accounting issues deal with holding and trading the cryptocurrencies. Because there is no on-point guidance, diversity in practice exists. Some treat cryptocurrencies like investments and measure them at fair value, though the absence of a contract makes this difficult to justify. Others view them as intangible assets, measured at lower of cost or market; when sold or exchanged for goods or services, this results in a substantial one-time gain that often does not reflect the economics of the transaction. Still, others would like to treat cryptocurrencies as currency, cash, or a cash equivalent, especially when the cryptocurrency is pegged to the US Dollar or other real currencies. Accounting issues are becoming more prevalent, as evidenced by an emerging and growing market for derivative instruments on cryptocurrency. Board members indicated that it may be a good first step to get a list of preparers that hold and trade cryptocurrency, speak with them, and understand how many companies have a material interest in cryptocurrency (FASB, 2018)

Based on this excerpt, a major issue that accounting professionals need guidance is the measurement and presentation of holding and trading cryptocurrencies, which needs to be addressed by the FASB for consistency in reporting these lucrative transactions. With this gap in the guidance, it opens the door for lack of uniformity when it comes to the opinions of accounting professionals actively dealing with cryptocurrencies in practice. Currently, PricewaterCoopers (2018) supports the notion that cryptocurrencies do not meet the definition of cash or cash equivalents, foreign currency, inventory, financial instruments, or a commodity, mostly because cryptocurrencies are not tangible and not backed by a form of government. As such, since they lack physical substance, it appears most companies are

reporting digital currency as intangible assets on the balance sheet. However, we found inconsistencies among companies. For example, we found that Overstock.com classifies its cryptocurrencies (such as 
Bitcoin) in the Prepaid and Other Current Assets section of the consolidated balance sheets. Additionally, gains or losses that result from cryptocurrencies were recorded in the Other Income (Expenses) section of the consolidated statements of operations. The justification and further discussion of this presentation/valuation were noted in their 10K:

"We hold cryptocurrency-denominated assets ("cryptocurrencies") such as bitcoin and we include them in Prepaids and other current assets in our consolidated balance sheets. Our cryptocurrencies were \$2.4 million and \$1.5 million at December 31, 2018 and 2017, respectively, and are recorded at cost less impairment. We recognize impairment on these assets caused by decreases in market value, determined by taking quoted prices from various digital currency exchanges with active markets, whenever events or changes in circumstances indicate that the carrying amount of an asset may not be recoverable. Such impairment in the value of our cryptocurrencies is recorded in General and administrative expense in our consolidated statements of operations. Impairments on cryptocurrencies were \$10.5 million for the year ended December 31, 2018. There was no impairment on cryptocurrencies during the years ended December 31, 2017 and 2016" (Overstock.com, 2019).

This issue is further complicated with the inclusion of 'initial coin offerings' and 'initial token offerings'. This type of cryptocurrency offerings is gaining traction in the global financial markets with over US\$22 billion raised to date as of December 2018 (Coindesk, 2018). Securities regulators have raised concerns related to such offerings because of issues surrounding volatility, transparency, valuation, custody, and liquidity, as well as the use of unregulated cryptocurrency exchanges. There is also a fundamental concern about whether these offerings constitute an offering of securities (SEC, 2018).

We next investigated the global impact that cryptocurrencies are presenting for accounting setting bodies. As a result of our review, we found that the accounting treatment of cryptocurrencies under International Financial Reporting Standards (IFRS) is unclear as well. The International Financial Standards Board (IFSB) has proactively produced a draft document for guidance in the reporting of cryptocurrency. The document provides an overview and description of cryptocurrency and general guidance regarding accounting methods and provides suggested guidance to classify cryptocurrency as an intangible asset. After a detailed review of this document, it was clear that they have only provided a broad overview of these issues and the actual guidance for accounting for cryptocurrency is lacking. Cryptocurrencies may not qualify as financial assets, as they neither represent a right to receive cash or other financial instruments nor a contract to exchange assets. Even though the guidance currently suggests they qualify as intangible assets, this does not fit the definition of an 'intangible asset' as documented in the current standards published by the IFSB. More specifically, they are not legally protected and have no useful life. As of today, there is not any consistency among countries in how they deal with cryptocurrencies and we can only speculate this is primarily due to the lack of guidance from the International Accounting Standards Board (IASB) regarding this topic. Refer to Figure 3 on how different countries approach crypto-regulations. 


\section{FIGURE 3 \\ CRYPTOCURRENCIES REGULATIONS BY COUNTRIES}

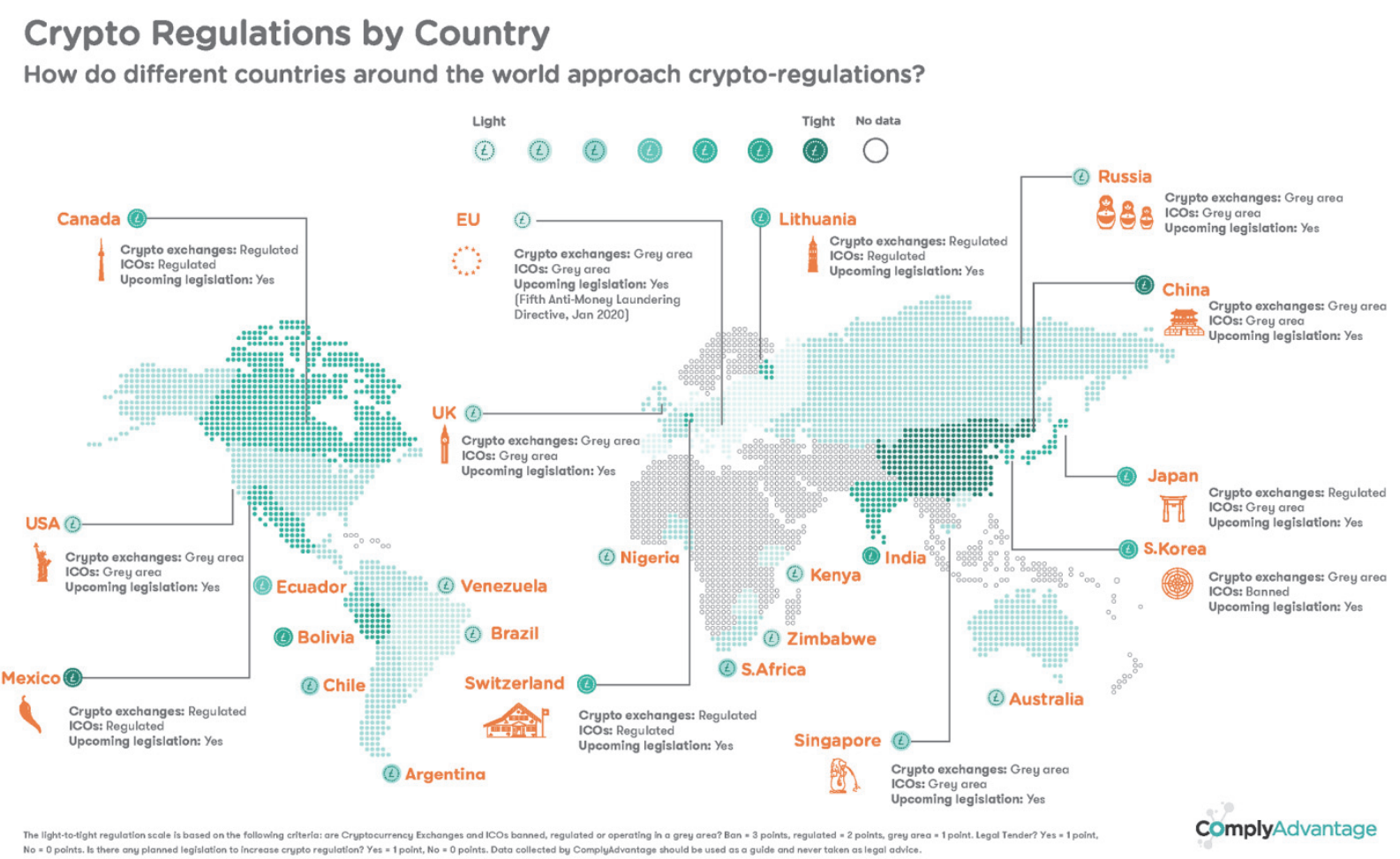

Source: ComplyAdvantage (2018). Cryptocurrency Regulations Around the World, Retrieved on January 7, 2019, https://complyadvantage.com/blog/cryptocurrency-regulations-around-world/

Unlike FASB and IFSB, we have found that the United States Internal Revenue Service has been more proactive in regulating cryptocurrencies. Notice 2014-21 treats cryptocurrencies as property rather than currency for federal tax purposes (Vetter, 2018). For example, Bitcoin sold for U.S. dollars is a noticeable capital gain or loss reportable on Form 8949. In a case, when a coin miner receives a coin for his/her work, s/he naturally recognizes revenue based on the value of the coin s/he received (Green, 2017). The most significant United States-based coin exchange is Coinbase. During November 2017, the court ordered Coinbase to provide IRS taxpayer ID, name, birth date, address, and historical transaction records for certain higher-transacting customers during the 2013-2015 period, which is a group of approximately 13,000 customers (Coinbase, 2018). For taxpayers who have unreported income from cryptocurrencies, the civil penalties for failure to comply include:

- Failure to file a tax return under Sec. 6651(a)(1): $5 \%$ of the unpaid tax per month, up to $25 \%$.

- Failure to pay taxes shown on the return under Sec. 6651(a)(2): 0.5\% per month of the unpaid tax, up to $25 \%$.

- Accuracy-related penalty under Sec. $6662: 20 \%$ or $40 \%$.

- Civil fraud penalties under Sec. 6651(f) or 6663: 75\% of the unpaid tax.

- Failure to file FBAR: Base penalty of $\$ 10,000$ per failure to report an account per year; increasing, if the failure is willful, to the greater of $\$ 100,000$ or $50 \%$ of the total balance of the foreign financial account per violation.

- Failure to file Form 8938: Base penalty of $\$ 10,000$ per failure to report an applicable asset, with an additional $\$ 10,000$ for each month the failure continues, beginning 90 days after the taxpayer is notified of the delinquency, up to a maximum of $\$ 50,000$. This list does not include possible criminal charges for tax evasion or other crimes (Polizzano, 2018). 
According to a report from the Wall Street Journal, starting on November 26, 2018, companies in the state of Ohio will be able to pay a variety of taxes with the cryptocurrency (Vigna, 2018). "Lawmakers in other U.S. states have also considered allowing crypto tax payments in the past. Back in March, Illinois and Arizona were both considering proposals to allow residents to pay their tax bills in bitcoin. Georgia was also considering the option in February" (Khatri, 2018).

Based on our review of the literature, the inclusion of cryptocurrencies in the classroom would require faculty to take a proactive approach to the valuation and presentation issues not yet fully addressed by standard setting bodies. Including current research and student perspectives on this relevant topic would not only prepare students for their future but also allow them to contribute to this important dialogue as these standards are being finalized.

\section{THE CASE STUDY REQUIREMENTS}

The goal of the case study was to introduce and integrate cryptocurrencies into the curriculum of an intermediate financial accounting class. Our assignment first required student self-study and investigation using a prescribed outline and followed up their research with a detailed, interactive discussion in the class. This case study was assigned as an extra credit assignment to 177 undergraduate accounting students (with a small sample of finance majors also taking the course), 117 students completed this assignment, and 71 students completed the survey. The details of the case are below.

\section{Research Assignment}

The research assignment portion of the case study was listed in the syllabus handed out at the beginning of the semester. This assignment represented extra credit points for approx. $1.7 \%$ of the total points for the course. We asked the students to investigate the prompted questions on their own and turn in a reflection report based on their findings. This report was used in the next step of the case study to facilitate the discussion in class. The questions that the students were asked to investigate were as follows:

1. What are cryptocurrencies?

2. Why are cryptocurrencies so buzzworthy?

3. How should cryptocurrencies be classified on the financial statements?

We designed the questions to keep the students focusing on cryptocurrencies in an accounting setting but also had them expand their search to other financial markets that they might be interested in or that may come up while they were researching. They were instructed to bring their finished papers to the class and participate in an interactive class discussion regarding their findings.

\section{Class Discussion}

Once the due date of the research assignment had passed, we devoted the following class period to thoroughly dissecting the findings of the students. We began the class period lecturing about the basics of cryptocurrencies and briefly highlighted the current regulation that addresses them. We then turned the discussion to the students. To promote an effective classroom discussion, we broke the students into groups and asked them to share their findings with their fellow classmates. More specifically, we focused the students to question (3) from their reflection papers and asked them, as a group, to determine where cryptocurrencies should be presented in financial statements. During the discussion, we noted that students were not only very involved in the debate (as there is no clear guidance as discussed in section II), but every group was reading both the FASB and IFRS statements to find the correct placement of these assets. Once the students came to a decision, we allowed them to share their findings with the rest of the class. Overall, these were the conclusions they described:

$>$ Is it cash or cash equivalent? No, it is not accepted as a legal tender and not backed by a government (ASC305, IAS7).

$>$ Is it inventory? No, it is not a tangible asset (ASC 310, IAS 2). 
Is it a financial instrument? No, it does not have a contractual right to receive or exchange cash or a financial instrument (ASC 326, IAS 9).

$>$ Is it an intangible asset? It meets a definition as it lacks physical substance (ASC350, IAS $38)$.

The final part of this discussion wrapped up with a real-world example of how cryptocurrencies could be presented on financial statements. We operationalized this topic by reviewing the $10 \mathrm{~K}$ for Overstock.com with the students and highlighting that Overstock.com classifies cryptocurrencies as 'Prepaids and Other Assets'. The goal was to give students an accurate portrayal of the discussions current accounting standard setting bodies are having and encourage them to actively consider how they would resolve these critical issues. From our perception, students appeared excited by the opportunity to fit cryptocurrencies into the existing US GAAP and IFRS and overall, they were actively engaged in this activity.

Directly after the discussion, we administered a voluntary survey to assess how they felt about the assignment overall. The results are discussed in the next section.

\section{STUDENT ASSESSMENT AND FEEDBACK}

The outcomes of our survey generated some interesting results. We first looked at the exposure the students had to cryptocurrencies prior to the assignment. Most of the students (76\%) had not taken any classes that had addressed cryptocurrency prior to the assignment and over half the class (55\%) had no prior knowledge of them. This supports our notion that cryptocurrency is not currently integrated into the classroom for accounting students and it gave us a reliable population to assess our case study. Additionally, in order to ensure our results captured students that were actively engaged in the class, we included questions that would reflect what we discussed in the class (see Q7 \& Q8 below).

The survey results confirmed that students were interested in learning more about cryptocurrencies (Q14) and that they felt this knowledge would be helpful to them in their future (Q15 and Q16). Interestingly, while the overwhelming majority felt that understanding Blockchain would give them an advantage in their future careers $(87 \%$ from Q15), the class was almost split down the middle as to whether they thought their future employers would expect them to understand Blockchain (Q18).

\begin{tabular}{lcc}
\multicolumn{1}{c}{ Answer Text } & Answer Count & Percentage \\
\hline Q1. Are you currently enrolled as a & & \\
\hline Full-time student (12 or more units) & 67 & $94.40 \%$ \\
Part-time student (less than 12 units) & 71 & $\mathbf{1 0 0 . 0 0 \%}$ \\
\hline Total & $580 \%$ \\
\hline Q2. Option Sought & 11 & $82.90 \%$ \\
\hline Accounting & 1 & $15.70 \%$ \\
Finance & $\mathbf{7 0}$ & $1.40 \%$ \\
Other & 54 & $\mathbf{1 0 0 . 0 0 \%}$ \\
\hline Total & 14 & $76.10 \%$ \\
\hline Q3. How many classes have you taken that covered Blockchain (i.e. cryptocurrencies)? & $19.70 \%$ \\
0 & 3 & $4.20 \%$ \\
\hline or more & $\mathbf{7 1}$ & $\mathbf{1 0 0 . 0 0 \%}$ \\
\hline Total & & \\
\hline
\end{tabular}


Answer Text

Answer Count

Percentage

Q4. Have you had any prior knowledge of cryptocurrencies?

\begin{tabular}{lcc}
\hline Yes & 32 & $45.10 \%$ \\
No & 39 & $54.90 \%$ \\
\hline Total & $\mathbf{7 1}$ & $\mathbf{1 0 0 . 0 0 \%}$ \\
\hline Q5. I feel that after cryptocurrency case assignment: (select the best option) & \\
\hline Increased my interest in Cryptocurrencies & 46 & $65.70 \%$ \\
Not affected my interest in Cryptocurrencies & 22 & $31.40 \%$ \\
Decreased my interest in Cryptocurrencies & 2 & $2.90 \%$ \\
\hline Total & $\mathbf{7 0}$ & $\mathbf{1 0 0 . 0 0 \%}$ \\
\hline Q6. After completing the cryptocurrencies case assignment, I feel that I have: (Mark all that apply) \\
\hline $\begin{array}{l}\text { Developed an appreciation for Accounting for } \\
\text { Cryptocurrencies }\end{array}$ & 20 & $28.60 \%$ \\
$\begin{array}{l}\text { Gained a new perspective towards Accounting for } \\
\text { Cryptocurrencies }\end{array}$ & 29 & $41.40 \%$ \\
$\begin{array}{l}\text { Become more aware of Accounting for } \\
\text { Cryptocurrencies }\end{array}$ & & $78.60 \%$ \\
$\begin{array}{l}\text { Developed skills that will help me in my future } \\
\text { career }\end{array}$ & 55 & $20.00 \%$ \\
\hline
\end{tabular}

Q7. The U.S. GAAP does not currently directly address the accounting for cryptocurrencies. Based on our class discussion, how should cryptocurrencies be generally accounted for

\begin{tabular}{lcc}
\hline Cash & 7 & $9.90 \%$ \\
Intangible asset & 56 & $78.90 \%$ \\
Inventory & 3 & $4.20 \%$ \\
Financial Instrument & 5 & $7.00 \%$ \\
\hline Total & $\mathbf{7 1}$ & $\mathbf{1 0 0 . 0 0 \%}$ \\
\hline Q8. How does Overstock.com classify cryptocurrencies on the balance sheet? & \\
\hline Cash & 12 & $17.10 \%$ \\
Inventory & 11 & $15.70 \%$ \\
Prepaids and other current assets & 37 & $52.90 \%$ \\
Commodity & 10 & $14.30 \%$ \\
\hline Total & $\mathbf{7 0}$ & $\mathbf{1 0 0 . 0 0 \%}$ \\
\hline Q9. Does the IRS have guidance in regards to cryptocurrencies? & $54.90 \%$ \\
\hline Yes & 39 & $45.10 \%$ \\
No & 32 & $\mathbf{1 0 0 . 0 0 \%}$ \\
\hline Total & $\mathbf{7 1}$ & \\
\hline
\end{tabular}


Answer Text Answer Count Percentage

Q10. Do you think initial coin offering (ICO) should be regulated in the U.S.?

$\begin{array}{lcc}\text { Yes, by the U.S. federal government } & 48 & 67.60 \% \\ \text { Yes, as determined by individual states } & 9 & 12.70 \% \\ \text { No } & 14 & 19.70 \% \\ \text { Total } & \mathbf{7 1} & \mathbf{1 0 0 . 0 0 \%}\end{array}$

Q11. Which of the following reasons to own Cryptocurrency? (Select all that apply)

As a growth investment $\quad 63 \quad 88.70 \%$

As a store value $\quad 22 \quad 31.00 \%$

$\begin{array}{lll}\text { To hedge against traditional asset crashes } & 27 & 38.00 \%\end{array}$

To avoid government regulation $\quad 25 \quad 35.20 \%$

To support the development of blockchain $\quad 33 \quad 46.50 \%$

Q12. How likely are you to invest in cryptocurrency in the next three years?

\begin{tabular}{lcc}
\hline 1 (less likely) & 12 & $16.90 \%$ \\
2 & 12 & $16.90 \%$ \\
3 & 29 & $40.80 \%$ \\
4 & 14 & $19.70 \%$ \\
5 (more likely) & 4 & $5.60 \%$ \\
\hline
\end{tabular}

Q13. How is important for students to understand blockchain (i.e. cryptocurrencies)

$\begin{array}{lcc}1 \text { (less important) } & 0 & 0.00 \% \\ 2 & 2 & 2.80 \% \\ 3 & 13 & 18.30 \% \\ 4 & 36 & 50.70 \% \\ 5 \text { (more important) } & 20 & 28.20 \%\end{array}$

Q14. Would you like to learn more about Blockchain (i.e. cryptocurrencies)?

\begin{tabular}{lcc}
\hline Yes & 63 & $88.70 \%$ \\
No & 8 & $11.30 \%$ \\
\hline Total & $\mathbf{7 1}$ & $\mathbf{1 0 0 . 0 0 \%}$ \\
\hline
\end{tabular}

Q15. Do you think knowledge of Blockchain (i.e. cryptocurrencies) will give you an advantage in your future workplace?

\begin{tabular}{lcc}
\hline Yes & 62 & $87.30 \%$ \\
No & 9 & $12.70 \%$ \\
\hline Total & $\mathbf{7 1}$ & $\mathbf{1 0 0 . 0 0 \%}$ \\
\hline
\end{tabular}

Q16. Do you think learning about this topic will benefit students like yourself in the future?

\begin{tabular}{lcc}
\hline Yes & 70 & $98.60 \%$ \\
No & 1 & $1.40 \%$ \\
\hline Total & $\mathbf{7 1}$ & $\mathbf{1 0 0 . 0 0 \%}$ \\
\hline
\end{tabular}


Q17. Why should you care about accounting for cryptocurrencies?

"We should care about accounting for cryptocurrencies because the usefulness of blockchain technology combined with an increasing public awareness of blockchain technologies is likely to increase the prevalence of cryptocurrencies in personal and business applications. Similarly, caring about cryptocurrencies is important because of its impact on the U.S. dollar since it is a non-central asset, and has a value that cannot be directly controlled by a government."

Q18. Do you think employers expect you to understand the basic of Blockchain (i.e. cryptocurrencies)?

\begin{tabular}{lcc}
\hline Yes & 34 & $48.60 \%$ \\
No & 36 & $51.40 \%$ \\
\hline Total & $\mathbf{7 0}$ & $\mathbf{1 0 0 . 0 0 \%}$ \\
\hline Q19. Did this case study benefit your knowledge of accounting in any & \\
way? & 62 & $88.60 \%$ \\
\hline Yes & 8 & $11.40 \%$ \\
No & $\mathbf{7 0}$ & $\mathbf{1 0 0 . 0 0 \%}$ \\
\hline Total & & \\
\hline Q20. Additional Comments
\end{tabular}

"I want to thank you for assigning this topic. I had heard of bitcoin, but I had never taken the time to learn more about it. Having learned that cryptocurrencies can be used in some state with in the U.S. as a form of payment, has made me understand that I need to learn a lot about this topic."

\section{CONCLUSIONS, LIMITATIONS, AND FURTHER RESEARCH}

The existence of Blockchain, including cryptocurrencies, holds in the business world today is undeniable. The natural step in this technological advancement is to incorporate these important topics into the curriculum of students in order to integrate early exposure and understanding of these complex issues. We found in this case study that by allowing students to research and read about accounting for cryptocurrencies on their own, it helped to facilitate a better conversation in the classroom and keeping students well-informed of important changes in accounting standards and regulations.

There are several limitations to our case study that should be addressed. As we introduced this topic during one semester, we had a limited sample of students taking intermediate accounting and brought a smaller sample size than we would have liked. Additionally, most of the students who take intermediate accounting are in the beginning of their junior year, which means they could be exposed to cryptocurrencies in other accounting or finance classes later in their educational career, although we are not currently aware of any other courses that address the issues presented in this case study.

The overall goal of this case study was to better understand the role cryptocurrencies play in the professional accounting world and to investigate the introduction into accounting classes. Our findings are a jumping-off point to promote and to encourage accounting faculty to prepare our students to adapt in the field and include cryptocurrencies as part of coursework moving forward. Per Smith (2018), this represents a challenge, since faculty members also need to educate themselves on these topics, but also is an opportunity for forward-looking educators to differentiate their courses and their students. We would also like to see further research concerning the perceptions of employers in regards to the level of knowledge regarding cryptocurrencies that they are expecting of students graduating with accounting degrees. 


\section{REFERENCES}

Annual report which provides a comprehensive overview of the company for the past year. (2018). Retrieved May 28, 2019, from http://investors.overstock.com/static-files/10e16ab3-5fc8-4fdb$8 \mathrm{a} 9 \mathrm{a}-\mathrm{dd} 84 \mathrm{~d} 2 \mathrm{~d} 48 \mathrm{~d} 7 \mathrm{c}$

Blockgeeks. (2018, September 13). What is Cryptocurrency: Everything You Must Need To Know! Retrieved May 28, 2019, from https://blockgeeks.com/guides/what-is-cryptocurrency/

Coinbase. (2018). IRS Notification. Retrieved May 28, 2019, from https://support.coinbase.com/customer/portal/articles/2924446-irs-notification

Coindesk. (2018). ICO Tracker. Retrieved May 28, 2019, from https://www.coindesk.com/ico-tracker

CoinMarketCap. (2019). Top 100 Cryptocurrencies by Market Capitalization. Retrieved May 28, 2019, from https:/coinmarketcap.com/

Complyadvantage. (2018, November 1). Cryptocurrency Regulations around the World. Retrieved Retrieved on May 28, 2019, from https://complyadvantage.com/blog/cryptocurrency-regulationsaround-world/

Deloitte. (2018). Classification of cryptocurrency holdings. Retrieved May 28, 2019, from https://www2.deloitte.com/us/en/pages/audit/articles/fra-classification-of-cryptocurrencyholdings.html

Deloitte. (2016, March). Blockchain Technology a game-changer in accounting? Retrieved May 28, 2019, from

https://www2.deloitte.com/content/dam/Deloitte/de/Documents/Innovation/Blockchain_A\%20ga me-changer\%20in\%20accounting.pdf

Drew, J. (2018, February 28). How AI, blockchain, and automation will reinvent accounting. Retrieved May 28, 2019, from https://www.journalofaccountancy.com/podcast/ai-blockchain-automationreinventing-accounting.html

Financial Accounting Standards Board. (2018, October 9). Minutes of the October 9, 2018 Private Company Council Meeting. Retrieved May 28, 2019, from https://www.fasb.org/jsp/FASB/Document_C/DocumentPage\&cid=1176171658882

Green, R. (2017, October 30). How Cryptocurrency Investors Can Avert IRS Attack. Retrieved May 28, 2019, from https://www.forbes.com/sites/greatspeculations/2017/10/30/how-cryptocurrencyinvestors-can-avert-irs-attack/\#7fd10500293f

Khatri, Y. (2018, November 26). Ohio Becomes First US State to Allow Taxes to Be Paid in Bitcoin. Retrieved May 28, 2019, from https:/www.coindesk.com/ohio-becomes-first-us-state-to-allowtaxes-to-be-paid-in-bitcoin

Milutinović, M. (2018). Cryptocurrency. Ekonomika, 64(1), 105-122.

Polizzano, B. (2018, October 1). Cryptocurrency: Compliance challenges and IRS enforcement. Retrieved May 28, 2019, from https://www.thetaxadviser.com/issues/2018/oct/cryptocurrency-compliancechallenges-irs-enforcement.html

Popper, N. (2015, May 15). Decoding the Enigma of Satoshi Nakamoto and the Birth of Bitcoin. Retrieved May 28, 2019, from https://www.nytimes.com/2015/05/17/business/decoding-theenigma-of-satoshi-nakamoto-and-the-birth-of-bitcoin.html

PricewaterhouseCoopers. (2018, March 6). Cryptocurrencies: Time to Consider Plan B. Retrieved May 28, 2019, from https://www.pwc.com/us/en/cfodirect/publications/point-of-view/cryptocurrencybitcoin-accounting.html

SEC. (2018, February 6). Chairman's Testimony on Virtual Currencies: The Roles of the SEC and CFTC. Retrieved May 28, 2019, from https://www.sec.gov/news/testimony/testimony-virtual-currenciesoversight-role-us-securities-and-exchange-commission

Smith, S. (2018, April 10). Bring Cryptocurrencies into the Accounting Classroom. Retrieved May 28, 2019, from https://www.journalofaccountancy.com/newsletters/extra-credit/cryptocurrencies-inthe-accounting-classroom.html 
Vetter, A. (2018, August 20). Blockchain, machine learning, and a future accounting. Retrieved May 28, 2019, from https://www.journalofaccountancy.com/newsletters/2018/aug/blockchain-machinelearning-futureaccounting.html?utm_source=mnl:cpainsider\&utm_medium=email\&utm_campaign=20Aug2018

Vetter, A. (2018, July 23). CPAs' top 5 questions about blockchain, cryptocurrencies. Retrieved May 28, 2019, from https://www.journalofaccountancy.com/newsletters/2018/jul/5-questions-blockchaincryptocurrencies.html?utm_source=mnl:cpainsider\&utm_medium=email\&utm_campaign=23Jul2 018

Vigna, P. (2018, November 26). Pay Taxes With Bitcoin? Ohio Says Sure. Retrieved May 28, 2019, from https://www.wsj.com/articles/pay-taxes-with-bitcoin-ohio-says-sure-1543161720

Zuckerman, M. (2018, January 15). 80\% Of All Bitcoins Already Mined, Only 4.2 Million Coins Left Until Supply Cap. Retrieved May 28, 2019, from https://cointelegraph.com/news/80-of-allbitcoins-already-mined-only-42-million-coins-left-until-supply-cap 